Theodore Friedmann, M.D.
Director
Program in Human Gene Therapy
University of California School of
Medicine, San Diego
Department of Pediatrics
La Jolla, CA 92093-0634
United States

\author{
1956 A.B., Chemistry, University of Pennsylvania, Philadelphia, \\ PA \\ 1960 M.D., University of Pennsylvania \\ 1960-1961 Intern in Pediatrics, Children's Hospital and Medical \\ Center, Boston, MA \\ 1961-1962 Resident in Pediatrics, Children's Hospital, Boston, MA \\ 1962-1963 U.S. Air Force, Captain 10th Tactical Hospital, Alconbury, \\ UK \\ 1963-1964 Research Fellow in Colloid Science, University of \\ Cambridge, Cambridge, UK \\ Biology, University of Cambridge \\ 1964 \\ 1964-1965 \\ 1965-1965 \\ $1965-1967$ \\ 1967-1968 \\ 1968-1969 \\ 1969-1973 \\ 1973 to 1981 \\ 1977 \\ 1981-present \\ 1984 \\ 1993-1998 \\ 1989-present \\ 1994-present \\ Senior Researcher in Pediatrics/Research Fellow, Children's \\ Hospital and Medical Center, Boston, MA \\ Fellow in Pediatrics and Research Fellow, Harvard \\ University, Cambridge, MA \\ Fellow in Laboratory of Chemical Biology, NIAMD, NIH, \\ Bethesda, MD \\ Medical Officer, Laboratory of Human Genetics, NIAMD, \\ $\mathrm{NIH}$ \\ Postdoctoral Fellow, The Salk Institute, La Jolla, CA \\ Assistant Professor of Pediatrics, University of California, \\ San Diego, La Jolla, CA \\ Associate Professor of Pediatrics, University of California, \\ San Diego \\ Biology, University of Cambridge \\ Professor of Pediatrics, University of California, San Diego \\ Pathology, University of Oxford, Oxford, UK \\ Co-leader of Cancer Genetics Program, University of \\ California, San Diego Cancer Center \\ Muriel Jeannette Whitehill Chair in Biomedical Ethics, \\ University of California, San Diego \\ Director, Program in Human Gene Therapy, University of \\ California, San Diego
}

Honors

1989-present

1992

1994-1995

1995-present

1998-present
Editor, Molecular Genetic Medicine and Adv. Genetics, Acad. Press

University of California Chancellor's Association Award for

Newton-Abraham Visiting Professor and Fellow, Lincoln

College, University of Oxford

Chairman, Scientific Advisory Board, Lesch Nyhan

Syndrome, Children's Research Foundation

Chairman, Government Affairs Committee, American

Society of Human Gene Therapy Excellence in Research

\section{In Vivo Gene Transfer with Retrovirus Vectors}

The efficient use of retrovirus and lentivirus vectors for in vivo gene delivery in gene therapy applications will be greatly facilitated by improved methods to characterize the bio-distribution and fate of the vectors after systemic administration and to understand the mechanisms that determine tissue tropism of vectors in vivo. We have been developing methods to detect virus particles in vivo that take advantage of the existence of the cell-derived membrane that the viruses acquire in the process of budding from producer cells. We have labeled virus particles with a fluorescent membrane marker and studied factors affecting the distribution and virus particle attachment to a variety of tissues, especially the vascular endothelium and the liver, after systemic administration of the fluorescent-tagged virus particles. Systematically delivered virus is rapidly cleared from the circulation concomitant with rapid uptake into tissues of the reticuloendothelial system, particularly the liver and spleen. Fluorescent particles are also found to associate with the microvascular endothelium by mechanisms that may involve Pselectin. 